Ann. Biol. anim. Bioch. Biophys., I969, 9 (I), 55-73.

\title{
RÉPARTITION DES CELLULES ENTRE LES TISSUS DU RAT ADULTE, PREALABLEMENT SOUMIS A UNE SOUS-NUTRITION ÉNERGÉTIQUE TEMPORAIRE A DEUX STADES DE LA CROISSANCE
}

\author{
G. DURAND, G. FAUCONNEAU ( $\left.{ }^{(}\right)$et Eliane PENOT \\ avec la collaboration technique de Noëlle BoURgEAux \\ Station centrale de Recherches de Nutrition, \\ Centre national de Recherches zootechniques, 78 - Jouy-en-Josas \\ Institut national de la Recherche agronomique
}

\section{SOMMAIRE}

Trois lots de rats reçoivent, ad libitum depuis le sevrage, un régime semi-synthétique équilibré contenant $\mathrm{I} 3 \mathrm{p}$. Ioo de matières azotées totales (régime témoin). Ils sont sacrifiés respectivement à $70 \mathrm{~g}, 200 \mathrm{~g}$ et $700 \mathrm{~g}$ et constituent les lots témoins.

Cinq autres lots dits expérimentaux, auparavant bien alimentés, sont maintenus pendant 42 jours à poids constant uniquement par réduction de l'apport des éléments énergétiques de la ration (glucides et lipides), les uns à $70 \mathrm{~g}$, les autres à $200 \mathrm{~g}$. A la fin de la période de restriction, un lot de chaque type est sacrifié. Les autres lots reçoivent de nouveau le régime témoin, et les derniers d'entre eux sont sacrifiés lorsqu'ils atteignent le poids de $700 \mathrm{~g}$.

Le corps des animaux est disséqué et partagé en plusieurs compartiments dans lesquels sont mesurées : - la teneur en ADN, proportionnelle au nombre de cellules - la valeur du rapport poids frais/ADN, proportionnelle à la taille des cellules, - les valeurs des rapports protéines/ADN et $A R N / A D N$, témoins de l'activité cellulaire.

Les animaux expérimentaux et témoins sont comparés à poids vif égal. Les principaux résultats montrent que :

- Le maintien à poids constant bloque l'hyperplasie et l'hypertrophie cellulaires, mais permet cependant aux animaux d'accumuler une certaine quantité de protéines et de minéraux, au détriment de l'eau et des lipides.

- La réalimentation ad libitum est suivie d'une période de 2 à 3 semaines pendant laquelle l'hyperplasie est particulièrement intense et l'accumulation de lipides excessive.

- Après cette phase de rattrapage très active, les animaux expérimentaux se développent, soit au même rythme que les témoins, soit peut-être un peu plus lentement, suivant que la restriction est imposée à la puberté ou au sevrage.

- Lorsque les animaux atteignent le poids de $700 \mathrm{~g}$, la quantité totale de protéines, de même que la répartition de celles-ci entre les divers compartiments corporels, sont à peu près équivalentes quel qu'ait été le traitement alimentaire antérieur. Les deux types d'animaux expérimentaux contiennent pratiquement la même quantité de cellules. Cependant, celles-ci sont plus abondantes, de Io $\mathrm{p}$. Ioo en moyenne, chez les témoins. Il n'est pas certain qu'un écart aussi faible doive être pris en considération. Les cellules sont réparties de la même façon entre les divers compartiments corporels des témoins et des expérimentaux.

(1) Adresse actuelle : Station a'Étude des Métabolismes. C. R. Z. V., 63-Theix, près Clermont-Ferrand. 


\section{INTRODUCTION}

Les effets d'une restriction alimentaire temporaire, appliquée à différents stades de la croissance, sur la croissance ultérieure des animaux, ont fait l'objet d'un certain nombre de travaux. A notre connaissance, il s'est toujours agi de restriction du niveau alimentaire; les animaux, auxquels ce type de restriction était imposé, étaient donc vraisemblablement victimes d'une sous-alimentation généralisée. Le plus souvent, la restriction était appliquée à trois stades différents : pendant la période d'allaitement, au sevrage et à la puberté.

La plupart des recherches effectuées ont eu pour but de déterminer les effets à long terme d'une carence nutritionnelle passagère sur l'anatomie, la composition corporelle et la taille finale des sujets expérimentaux. Widdowson et MCCANCE (I963), WidDowson et KENNEDY (I962), LisTER et MCCANCE (I965-I967) concluent de leurs travaux que la sous-alimentation généralisée influe défavorablement sur les capacités ultérieures de croissance et que les effets sont d'autant plus marqués que la sous-nutrition est imposée à un stade plus précoce du développement. Ces auteurs montrent également que sous certaines conditions, il est possible de modifier la taille finale des animaux. Les animaux de taille réduite possèdent les formes et les proportions des animaux témoins de même poids. I,e rapport musculature/squelette n'est pas changé, mais la proportion de tissus adipeux est un peu augmentée. WinIcK et NoBLE (I966-I 967) estiment comme les auteurs précédents que les tailles finales des animaux expérimentaux et témoins sont d'autant plus différentes que la restriction est appliquée précocement; ils tentent de donner une explication de ce fait expérimental en s'appuyant sur des résultats montrant l'évolution différente de 1'hyperplasie dans quelques organes des témoins et des restreints.

Dans le présent travail, nous nous proposons d'étudier les effets, non pas d'une sous-alimentation généralisée, mais d'une restriction uniquement énergétique, limitée en temps, sur la croissance ultérieure du Rat. La restriction énergétique est appliquée à des animaux âgés de 4 semaines (stade prépubère) et de 7 semaines (stade pubère) ; ses effets à long terme sont estimés par des mesures pondérales et par les teneurs en acides nucléiques et en protéines des principaux compartiments corporels. Ceci nous permet d'apprécier : - le nombre de cellules, proportionnel aux quantités d'ADN - la taille des cellules, proportionnelle au rapport poids frais/ADN, - les teneurs des cellules en protéines et en ARN, respectivement proportionnelles au rapport protéines/ADN et ARN/ADN.

\section{MATÉRIEI, ET MÉTHODES}

\section{Matériel animal}

Huit lots de Io à 15 rats mâles Wistar, dont les caractéristiques d'âge et de poids sont portées dans le tableau $\mathrm{I}$, sont utilisés. A l'intérieur de chaque lot, on ne conserve pour les études analytiques que les animaux dont le poids s'écarte de moins de $5 \mathrm{p}$. Ioo de la moyenne. 
Les rats sont pesés chaque matin jusqu'à $200 \mathrm{~g}$, tous les quatre jours au-delà. Avec ces huit lots on définit trois parcours.

Parcours $A$. - Trois lots reçoivent ad libitum un régime semi-synthétique équilibré à I3 $\mathrm{p}$. 100 de matières azotées $(\mathrm{N} \times 6,25)$. La composition du régime est portée dans le tableau 2 . Un lot est sacrifié à $70 \mathrm{~g}$ (lot $\mathrm{I}_{\mathrm{A}}$ ); le second à $200 \mathrm{~g}\left(\right.$ lot $\left.\mathrm{II}_{\mathrm{A}}\right)$ et à $700 \mathrm{~g}\left(\operatorname{lot} \mathrm{III}_{\mathrm{A}}\right)$. Ces trois lots sont dits lots témoins.

\section{TABLEAU I}

Numérotation et caractéristiques des lots au moment de l'abattage

\begin{tabular}{|c|c|c|c|c|c|c|c|c|}
\hline No des lots & $\mathbf{I}_{\mathbf{A}}$ & $\mathrm{I}_{\mathrm{B}}$ & $\mathrm{II}_{\mathrm{A}}$ & $\mathrm{II}_{\mathbf{B}}$ & $\mathrm{II}_{\mathrm{C}}$ & $\mathrm{III}_{\mathbf{A}}$ & $\mathrm{III}_{\mathbf{B}}$ & $\mathrm{III}_{\mathrm{C}}$ \\
\hline Poids vif $(\mathrm{g})$ & 71 & 72 & 200 & 200 & 201 & 696 & 692 & 700 \\
\hline $\operatorname{PVR}\left({ }^{(1)}(\mathrm{g}) \ldots\right.$ & - & - & - & - & - & 678 & 675 & 681 \\
\hline PVR $\%$ poids vif .... & - & - & - & 一 & - & 97,4 & 97,5 & 97,3 \\
\hline Age (jours) ........... & 28 & 70 & 50 & 8' & 92 & 288 & 338 & 312 \\
\hline Nombre d'animaux ... & 11 & 11 & 8 & 8 & 8 & 4 & 6 & 6 \\
\hline
\end{tabular}

(I) PVR $=$ Poids vif reconstitué (obtenu en additionnant les poids frais des divers compartiments corporels pesés après dissection).

Parcours B. - Trois lots reçoivent le régime témoin jusqu'à $70 \mathrm{~g}$, puis sont maintenus pendant 42 jours à ce poids. Au bout de ce temps un lot $\left(I_{B}\right)$ est sacrifié. Les deux autres reçoivent alors le régime témoin à volonté et sont sacrifiés l'un à $200 \mathrm{~g}$ (lot $\mathrm{II}_{\mathrm{B}}$ ), l'autre à $700 \mathrm{~g}$ (lot $\mathrm{III}_{\mathrm{B}}$ ).

TABLEAU 2

Composition centésimale du régime témoin

\begin{tabular}{|c|c|}
\hline & p. 100 \\
\hline 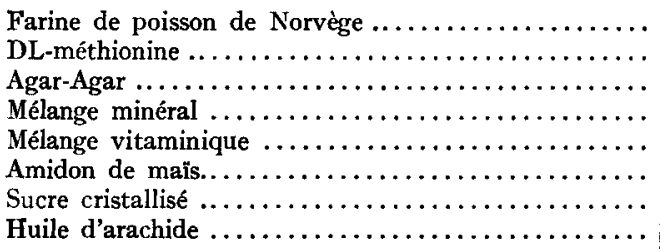 & $\begin{array}{l}16,0 \\
0,12 \\
2 \\
3 \\
1 \\
46,7 \\
22 \\
9,2\end{array}$ \\
\hline
\end{tabular}

Parcours C. - Deux lots reçoivent le régime témoin jusqu'à $200 \mathrm{~g}$, puis sont maintenus à ce poids pendant 42 jours. Au bout de ce temps, un lot est sacrifié (lot II $\mathrm{C}$ ), l'autre reçoit à nouveau le régime témoin et on le sacrifie à $700 \mathrm{~g}$ (lot III $_{\mathrm{C}}$ ).

Outre les trois parcours $\mathrm{A}, \mathrm{B}$ et $\mathrm{C}$, on définit également trois séries :

Série I : animaux de $70 \mathrm{~g}$
Série II : animaux de $200 \mathrm{~g}$
Série III : animaux de $700 \mathrm{~g}$

Distribution des aliments et mesure des consommations.

La consommation des animaux nourris ad libitum est mesurée.

Pour maintenir les animaux à poids constant on leur distribue chaque jour la même quantité 
de protéines, minéraux et vitamines que consommeraient des animaux témoins de même poids. Les besoins en ces éléments sont donc largement couverts. La quantité d'éléments énergétiques (mélange d'amidon de maïs, sucre cristallisé et huile d'arachide) est ajustée chaque jour de façon à ce que le poids des animaux pesés à jeun chaque matin reste constant. La proportion entre les divers éléments énergétiques est toujours respectée.

\section{Abattage et prélèvements.}

Pour les séries I et $I I$. - Chaque animal, sous anesthésie à l'éther, est saigné. Le foie est prélevé, rincé au sérum physiologique à $0^{\circ} \mathrm{C}$, essuyé, pesé et plongé dans l'azote liquide. Tous les organes de l'abdomen et de la cage thoracique, ainsi que les organes génitaux sont enlevés. Il reste alors le corps éviscéré. L'ensemble de la musculature des membres postérieurs est ensuite disséqué aussi rapidement que possible. Cette musculature d'une part et ce qui reste du corps éviscéré d'autre part sont pesés et refroidis par l'azote liquide. Pour chaque lot, l'ensemble des foies, de la musculature des membres postérieurs, des corps éviscérés sans cette musculature, sont séparément rassemblés. On obtient ainsi trois échantillons qui seront analysés.

Pour la série $I I I$. - Pour mieux définir la répartition des acides nucléiques et des protéines entre les divers tissus lorsque les animaux sont parvenus à l'âge adulte, et ce en fonction des conditions nutritionnelles préalablement imposées, les animaux sont disséqués en six parties distinctes :

I. la peau,

2. les dépốts adipeux comprenant : les dépôts adipeux sous-cutanés, périrénaux, épididymaires et mésentériques,

3. le foie,

4. les viscères et le sang,

5. la musculature des membres postérieurs,

6. la carcasse, c'est-à-dire ce qui reste du corps de l'animal, et qui comprend essentiellement le squelette et la musculature (moins la musculature des membres postérieurs).

Chaque partie est pesée et refroidie dans l'azote liquide. Pour chaque lot, ces six fractions sont séparément rassemblées. On obtient ainsi six échantillons qui seront analysés. Lorsque les traitements ne peuvent être effectués immédiatement, ils sont conservés à $-18^{\circ} \mathrm{C}$.

\section{Méthodes analytiques}

Les méthodes analytiques ont déjà été décrites (Durand et $a l ., 1965$ ). Bien que les principes généraux sur lesquels elles sont fondées n'aient pas varié, des modifications techniques importantes ont été apportées, qui nous obligent à une nouvelle description détaillée.

\section{I. Échantillonnage.}

Lorsque le poids frais de la fraction à analyser dépasse $150 \mathrm{~g}$, celle-ci est hachée à froid au moyen d'un hachoir (Scharfen). Généralement, une prise de Ioo $\mathrm{g}$ du hachis est prélevée pour être soumise aux traitements décrits ci-dessous. Lorsque le poids de la fraction est égal ou inférieur à $15 \circ \mathrm{g}$, celle-ci est entièrement retenue aux fins d'analyse.

Dans le cas de tissus adipeux, on prélève jusqu'à $400 \mathrm{~g}$ quand cela est possible, en raison du faible rendement de ces tissus en composés non lipidiques.

\section{Extraction des éléments acido-solubles.}

En général, une prise de $100 \mathrm{~g}$ de hachis est broyée dans des pots de mixeurs (Turmix) en présence d'acide trichloracétique (ATC) à 1o $\mathrm{p}$. 100 refroidi à $0^{\circ} \mathrm{C}$. On utilise $600 \mathrm{ml} \mathrm{d}$ ATC pour $100 \mathrm{~g}$ de tissu frais. On effectue trois broyages successifs de une minute à $\mathrm{I}_{4} 000 \mathrm{t} / \mathrm{min}$. Les broyats sont centrifugés pendant Io minutes à i $800 \mathrm{~g}$ (centrifugeuse MSE major refroidie à $-2^{\circ} \mathrm{C}$ ). Le surnageant est filtré. Cette opération est répétée trois fois. Les trois surnageants contenant les éléments acidosolubles sont écartés.

Dans le cas des tissus adipeux, la trop grande proportion de lipides ne permet pas de réaliser convenablement l'extraction décrite précédemment, aussi convient-il de procéder à un dégraissage partiel préalable. Pour cela, les fractions de tissu adipeux haché sont agitées pendant 18 heures en présence du mélange méthanol-chloroforme (Iv/2v) refroidi. On utilise $600 \mathrm{ml}$ de mélange méthanolchloroforme pour roo $\mathrm{g}$ de tissu adipeux. On centrifuge ensuite, et le surnageant est écarté. L'extraction par l'ATC est effectuée sur le culot, comme cela est décrit ci-dessus. 


\section{Extraction des lipides.}

Les culots obtenus après l'extraction par l'ATC sont neutralisés par le mélange méthanol-acétate de sodium $\mathrm{N}$ à $\mathrm{pH} 7$. Ils sont ensuite dégraissés par le mélange méthanol-chloroforme (Iv/2v). Deux traitements successifs sont effectués avec agitation continue. Le premier pendant $\mathrm{x}$ heure, le second pendant la durée de la nuit. On utilise $\mathrm{I} 000 \mathrm{ml}$ du mélange pour une prise initiale de $100 \mathrm{~g}$ de tissu frais. Chacun des traitements est suivi d'une centrifugation à i $800 \mathrm{~g}$. Les résidus dégraissés sont soumis à un lavage à l'éthanol à $100^{\circ}$ et de nouveau centrifugés.

\section{Séchage et broyage.}

Ensuite, les résidus sont placés sur Büchner et lavés sous vide à l'éther sulfurique, puis séchés, également sous vide, dans un dessiccateur. Finalement, les résidus secs sont pesés puis réduits en poudre avec un broyeur à billes (Dangoumau). La poudre obtenue, homogène, est appelée " poudre sèche et dégraissée "; elle contient les protéines, les acides nucléiques et une partie des sels minéraux ; cette poudre peut être conservée à $-\mathrm{I} 8^{\circ} \mathrm{C}$.

\section{Séparation et dosage de l'ARN et de l'ADN à partir de la poudre sèche et dégraissée.}

a) Hydrolyse de l'ARN. - L'ARN est séparé de l'ADN par une hydrolyse alcaline, suivant la méthode de SCHMidT et TANnhauser (I945). Dans des béchers de $150 \mathrm{ml}$, on ajoute $50 \mathrm{ml}$ de $\mathrm{NaOH}$ $0,5 \mathrm{~N}$ à une quantité de poudre sèche variant de I à $2 \mathrm{~g}$ suivant la richesse supposée du tissu originel en acides nucléiques. Les béchers sont placés au bain-marie à $37^{\circ}$ pendant 18 heures. Une agitation permanente est entretenue par des agitateurs magnétiques. Au bout du temps requis, les hydrolysats sont neutralisés par l'acide formique I3 $\mathrm{N}$. Ensuite, on ajoute à chaque hydrolysat une solution d'ATC à $40 \mathrm{p}$. I00 en quantité suffisante pour obtenir une concentration finale de Io p. I00 (22 à 24 $\mathrm{ml})$ : les protéines et $1^{\prime} \mathrm{ADN}$ précipitent. Après ro minutes de contact à $0^{\circ} \mathrm{C}$, on centrifuge à $23^{\circ 0} \mathrm{~g}$ pendant ro minutes. Les culots sont lavés trois fois à l'ATC ı० p. Ioo. On recueille les surnageants qui contiennent les mononucléotides constitutifs de l'ARN; on les filtre et on les amène à un volume choisi $(200 \mathrm{ml})$ avec de l'eau bidistillée.

b) Hydrolyse de l'ADN. - Une hydrolyse de l'ADN convenablement choisie libère quantitativement les bases puriques (LEvène et BASS, I93I ; Colowick et KAPLAN, I957). Le culot résultant de la précipitation de l'ADN et des protéines par l'ATC est hydrolysé par 50 ml de $\mathrm{ClO}_{4} \mathrm{H} 0,5 \mathrm{~N}$ pendant 75 minutes au bain-marie bouillant. Après centrifugation de to minutes à $2300 \mathrm{~g}$ à $0^{\circ} \mathrm{C}$, les culots sont remis en suspension avec $50 \mathrm{ml}$ de $\mathrm{ClO}_{4} \mathrm{H} 0,5 \mathrm{~N}$ et hydrolysés à nouveau pendant 60 minutes au bain-marie. Après un dernier lavage des culots avec $30 \mathrm{ml}$ de $\mathrm{ClO}_{4} \mathrm{H} 0,5 \mathrm{~N}$, les surnageants sont rassemblés, filtrés et ajustés à ${ }_{5} 5^{\circ} \mathrm{ml}$ avec de l'eau bidistillée.

\section{Dosage des acides nucléiques.}

$A R N$. - Les mononucléotides contenus dans l'hydrolysat d'ARN sont fixés sur colonnes de résine Dowex I $\times 8$ (minus $400 \mathrm{mesh}$ ) sous forme $\mathrm{HCOO}^{-}$. Les colonnes ont une hauteur utile de $40 \mathrm{~cm}$, un diamètre intérieur de $9 \mathrm{~mm}$ (volume utile de $25 \mathrm{ml}$ ). Elles reçoivent une charge de 150 à $200 \mathrm{D}$. O. à $260 \mathrm{~m} \mu$. L'élution des monoribonucléotides est effectuée par deux systèmes de gradient linéaire. Le premier système (flacon principal : $\mathrm{HCOOH}_{2} \mathrm{~N}$; flacon mélangeur : eau ; volume par flacon : $250 \mathrm{ml}$ ) élue successivement le CMP et l'AMP. Le second système (flacon principal : $\mathrm{CHO}_{2} \mathrm{NH}_{4} 2 \mathrm{~N}-\mathrm{HCOOH}$ $0,15 \mathrm{~N}$; flacon mélangeur: $\mathrm{CHO}_{2} \mathrm{NH}_{4} 0,2 \mathrm{~N}-\mathrm{HCOOH} 0,06 \mathrm{~N}$; volume par flacon $300 \mathrm{ml}$ ) élue successivement le pseudo-UMP, l'UMP et le GMP. L'élution se fait sous pression (pompe Sigmamotor, débit roo $\mathrm{ml} /$ heure). A la sortie de colonne, la localisation des fractions éluées est déterminée par leur passage dans la cellule d'un absorptiomètre UV. LKB Uvicord muni d'un enregistreur (Bauer). Un collecteur (Seive) recueille les éluats par fraction de $4 \mathrm{ml}$. La quantité de chaque mononucléotide, exprimée en $\mu \mathrm{M}$, est mesurée au spectrophotomètre (JoBIN et YvoN) ( ${ }^{(1)}$.

$A D N$. - Les bases puriques provenant de l'hydrolyse de l'ADN sont fixées sur colonnes de résine échangeuse de cations Amberlite IR I 20 (200-400 mesh). Les colonnes ont une hauteur utile de $30 \mathrm{~cm}$, un diamètre intérieur de $9 \mathrm{~mm}$ (volume utile $20 \mathrm{ml}$ ). Elles reçoivent une charge de 200 à $250 \mathrm{D}$. $\mathrm{O}$, à $260 \mathrm{~m} \mu$. L'élution des bases puriques est effectuée sous pression (pompe Sigmamotor, débit $300 \mathrm{ml} /$ heure) au moyen d'un gradient linéaire d'HCl (flacon principal : $\mathrm{HCl}_{4} \mathrm{~N}$; flacon mélangeur $\mathrm{HCl} 0,75 \mathrm{~N}$; volume par flacon $400 \mathrm{ml}$ ). Un collecteur recueille l'éluat par fraction de $10 \mathrm{ml}$. La quantité de chacune des deux bases, exprimée en $\mu \mathrm{M}$, est mesurée par spectrophotométrie (2). On en déduit la quantité d'ADN par $\mathrm{g}$ de poudre sèche et dégraissée en appliquant la relation :

$$
\mathrm{ADN}=\text { (adénine }+ \text { guanine) } \times 2 \text { (ChargafF et LIPShitz, 1953) }
$$

(') Coefficients d'extinction molaire à $260 \mathrm{m \mu}: \mathrm{CMP}: 7$ à pH I ; AMP : 14,6 à pH 2,5; pseudo-UMP 8,5 à $\mathrm{pH} 4 ; \mathrm{UMP}: 9,9$ à pH 4,$5 ; \mathrm{GMP}:$ i I,6 à $\mathrm{pH} 4,7$. $3,5 \mathrm{~N}$.

(2) Coefficients d'extinction molaires à $260 \mathrm{~m} \mu$ : guanine : II,05 dans $\mathrm{HCl} 2,4 \mathrm{~N}$; adénine : II, 7 dans $\mathrm{HCl}$ 
7. Dosage de l'azote acido-précipitable.

L'azote est dosé sur la poudre sèche et dégraissée par la méthode Kjeldahl. La poudre ne contient plus comme source d'azote que des protéines et des acides nucléiques. La plus grande part de l'azote dosé est fournie par les protéines ( 90 à $98 \mathrm{p}$. 100) dont on détermine la quantité par le produit $\mathrm{N} \times 6,25$.

Composition globale des carcasses des séries I et II.

Dans des fractions de hachis pesant $5 \mathrm{~g}$ environ, on mesure les taux :

d'eau, par chauffage à l'étuve à $98^{\circ} \mathrm{C}$ pendant 24 heures ;

de cendres, par calcination à $53^{\circ} \mathrm{C}$ pendant $\mathrm{I}_{5}$ heures ;

de matières azotées totales $(\mathrm{N} \times 6,25)$, par la méthode Kjeldahl.

Le taux de lipides est calculé par différence.

\section{RÉSULTATS}

\section{Expression des résultats}

Les lots d'animaux sont comparés à poids égal.

Les quantités d'acides nucléiques sont exprimées par la somme en micromoles $(\mu \mathrm{M})$ de leurs bases constitutives. Il est aisé de transformer ces données en $\mu \mathrm{g}$ de P-ADN ou P-ARN en les multipliant par 3 I.

Parmi les résultats portés dans les tableaux $5-6-7$, le poids sec et dégraissé total (poids SD total) est déduit de la valeur du rapport poids SD p. Ioo poids frais, mesuré par pesées avant et après les extractions.

Les quantités totales de protéines et d'ADN sont calculées par les produits : poids $\mathrm{SD} \times$ protéines $/ g$ et poids $\mathrm{SD} \times \mathrm{ADN} / \mathrm{g} \mathrm{SD}$.

Pour la série III, la somme des poids frais mesurée des 6 compartiments constitués pour chaque lot est appelée " poids vif reconstitué " (PVR). Ce dernier est inférieur au poids vif réel de 2,6 à 2,4 p. Ioo (tabl. I). Ces pertes faibles et au demeurant peu différentes d'un lot à l'autre, s'expliquent facilement par évaporation d'eau. au cours de la dissection. Dans les tableaux 4 et 5 , les poids frais donnés pour chaque compartiment corporel analysé sont donc légèrement inférieurs à la réalité, mais comparables entre eux. En revanche, le poids sec et dégraissé, de même que les quantités d'acides nucléiques et de protéines, sont exacts.

\section{r. - Consommation}

Les courbes représentant les variations de la consommation des animaux nourris ad libitum en fonction de leur poids sont représentées sur la figure $\mathrm{I}$.

Parcours A. - La courbe de consommation des témoins est de forme classique (Durand et al., Ig66).

Parcours B. - Pour maintenir les jeunes animaux à $70 \mathrm{~g}$, on leur alloue au début de l'expérience $30 \mathrm{p}$. Ioo des éléments énergétiques (glucides et lipides) que consommeraient des témoins de même poids. Ce taux doit être progressivement diminué jusqu'à $I 5 p$. Ioo au cours du premier mois et maintenu à ce niveau jusqu'à l'échéance des 42 jours. Au cours des deux premières semaines qui suivent la réali- 
mentation, les animaux manifestent un très grand appétit et consomment autant que des témoins de $200 \mathrm{~g}$. Ensuite, leur consommation devient légèrement inférieure à celle des témoins de même poids.

Parcours C. - Pour maintenir les animaux à $200 \mathrm{~g}$, on leur distribue $40 \mathrm{p}$. Ioo des éléments énergétiques que consommeraient des témoins de même poids. Au moment de la réalimentation, les animaux $\mathrm{C}$ consomment $44 \mathrm{p}$. Ioo de plus que les témoins de même poids, mais cet écart diminue rapidement et disparaît vers $360 \mathrm{~g}$. Dès lors, les courbes de consommation relatives aux parcours $\mathrm{C}$ et $\mathrm{A}$ se confondent.

\section{2. - Coubes DE CRoissance (fig. 2)}

Parcours $A$. - Les animaux témoins présentent une courbe de croissance de forme sigmoïde classique. La vitesse de croissance, avec un gain de poids de $6 \mathrm{~g} / \mathrm{jour}$ entre 70 et $200 \mathrm{~g}$ est satisfaisante.

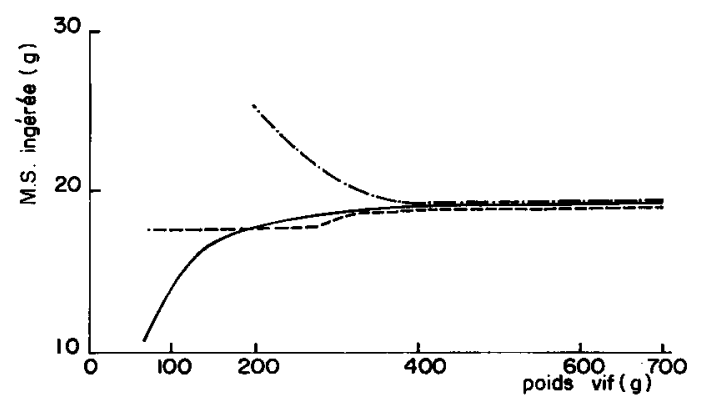

FIG. 1. - Consommation journalière (en g de matière sèche) en fonction du poids vif, de rats alimentés ad libitum a) continuellement ; $b$ ) après avoir été maintenus pendant 42 jours à $70 \mathrm{~g} ; c)$ après avoir été maintenus à $200 \mathrm{~g}$ pendant 42 jours.

Le maintien à poids constant est obtenu uniquement par réduction des éléments énergétiques de la ration (lipides et glucides).

$$
\text { a) ——- }
$$

Parcours $B$. - Lorsque les animaux sont réalimentés à volonté, leur croissance initiale leur permet de passer de 70 à $200 \mathrm{~g}$ en 15 jours, soit un gain de poids moyen de $8,7 \mathrm{~g} /$ jour ; peu après $200 \mathrm{~g}$, leur vitesse de croissance devient un peu plus faible que celle des témoins de même poids. La courbe de croissance fait apparaître

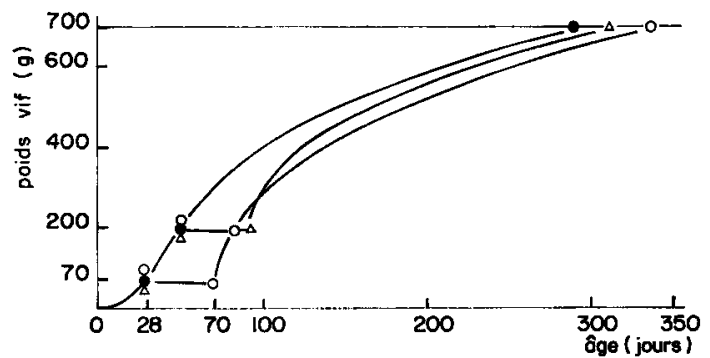

Fic. 2. - Courbes de croissance: a) rats continuellement bien alimentés (témoins) (•); $b$ ) maintenus pendant 42 jours à $70 \mathrm{~g}(0) ; c)$ maintenus pendant 42 jours à $200 \mathrm{~g}(\Delta)$.

Le maintien à poids constant est obtenu uniquement par réduction des éléments énergétiques de la ration (lipides et glucides). 


\section{TABLEAU 3}

Corps éviscéré des séries $I$ et II

a) Composition globale des corps éviscérés des séries I et II

\begin{tabular}{|c|c|c|c|c|c|}
\hline No des lots & $\mathbf{I}_{\mathbf{A}}$ & $\mathrm{I}_{\mathrm{B}}$ & $\mathrm{II}_{\mathrm{A}}$ & $\mathrm{II}_{\mathrm{B}}$ & $\mathrm{II}_{\mathrm{C}}$ \\
\hline Poids vif $(g) \ldots \ldots \ldots$ & 71 & 72 & 200 & 200 & 201 \\
\hline Poids du corps éviscéré (g) & 48 & 48 & 145 & 145 & 146 \\
\hline $\begin{array}{l}\text { Eau }(\%) \ldots \ldots \ldots \ldots \ldots \\
\text { Lipides }(\%) \ldots \ldots \ldots \ldots \\
\text { M. A. T. }(\%)(\mathbf{1}) \ldots \ldots \ldots \\
\text { Cendres }(\%) \ldots \ldots \ldots \ldots\end{array}$ & $\begin{array}{r}70,9 \\
8,0 \\
17,8 \\
3,3\end{array}$ & $\begin{array}{r}66,3 \\
5,0 \\
21,9 \\
6,7\end{array}$ & $\begin{array}{r}64,8 \\
13,5 \\
18,5 \\
3,2\end{array}$ & $\begin{array}{r}56,4 \\
23,8 \\
16,5 \\
3,3\end{array}$ & $\begin{array}{r}62,2 \\
8,2 \\
24,0 \\
5,6\end{array}$ \\
\hline
\end{tabular}

b) Différences de composition globale, exprimées en valeurs absolues, entre les corps éviscérés de rats des différents lots expérimentaux.

\begin{tabular}{|c|c|c|c|c|c|}
\hline & $\mathbf{I}_{B}-\mathbf{I}_{\mathbf{A}}$ & $\mathrm{II}_{\mathbf{C}}-\mathrm{II}_{\mathbf{A}}$ & $\mathrm{II}_{\mathrm{A}}-\mathrm{I}_{\mathrm{A}}$ & $\mathrm{II}_{\mathrm{B}}-\mathrm{I}_{\mathrm{B}}$ & $\mathrm{II}_{\mathbf{B}}-\mathrm{II}_{\mathbf{A}}$ \\
\hline $\begin{array}{l}\text { Eau (g) } \ldots \ldots \ldots \ldots \ldots \ldots \\
\text { Lipides (g) } \ldots \ldots \ldots \ldots \ldots \ldots \\
\text { M. A. T. }\left({ }^{(1)}(g) \ldots \ldots \ldots \ldots\right. \\
\text { Cendres }(g) \ldots \ldots \ldots \ldots \ldots\end{array}$ & $\begin{array}{r}-2,4 \\
-1.4 \\
+1,9 \\
+1,6\end{array}$ & $\begin{array}{l}-3 \\
-7,5 \\
+\quad 8,2 \\
+\quad 3,6\end{array}$ & $\begin{array}{r}+\quad 59,6 \\
+\quad 15,7 \\
+\quad 18,2 \\
+\quad 3,0\end{array}$ & $\begin{array}{r}+\quad 49,9 \\
+\quad 32,1 \\
+\quad 13,4 \\
+\quad 1,6\end{array}$ & $\begin{array}{l}12,1 \\
+\quad 15,0 \\
-\quad 2,9 \\
+\quad 0,2\end{array}$ \\
\hline
\end{tabular}

c) Composition globale du croît quotidien du corps éviscéré de rats dont le poids passe de 70 à $200 \mathrm{~g}$ - en croissance normale (parcours A) - en croissance compensatrice (parcours B).

\begin{tabular}{|c|c|c|c|}
\hline & $\frac{\mathrm{II}_{\boldsymbol{\Lambda}}-\mathrm{I}_{\mathbf{A}}}{22}$ & $\frac{\mathrm{II}_{\mathrm{B}}-\mathrm{I}_{\mathrm{B}}}{15}$ & \\
\hline $\begin{array}{l}\text { Eau }(g) \ldots \ldots \ldots \ldots \ldots \ldots \\
\text { Lipides }(g) \ldots \ldots \ldots \ldots \ldots \\
\text { M. A. T. }{ }^{(1)}(g) \ldots \ldots \ldots \ldots \\
\text { Cendres }(g) \ldots \ldots \ldots \ldots \ldots\end{array}$ & $\begin{array}{l}+2,71 \\
+0,71 \\
+0,83 \\
+0,14\end{array}$ & $\begin{array}{l}+3,32 \\
+\quad 2,14 \\
+0,89 \\
+\quad 0,11\end{array}$ & \\
\hline
\end{tabular}

(I) M.A.T. = Matières azotées totales $\mathrm{N} \times 6,25$. 
trois phases : une phase de croissance très rapide, mais auto-retardée (concavité de la courbe vers le bas), une phase peil accusée et fugace de croissance auto-accélérée et finalement une phase de croissance auto-retardée un peu plus lente que celle des témoins de même poids.

Parcours C. - Lorsque les animaux $\mathrm{C}$ sont réalimentés à volonté, leur croissance est passagèrement très supérieure à celle des témoins de même poids (II $g$ au lieu de $6,5 \mathrm{~g} / \mathrm{jour}$ ). Puis 1'écart s'atténue peu à peu et à partir de $360 \mathrm{~g}$ environ, les animaux $A$ et $C$ de même poids croissent au même rythme. $L_{a}$ forme de $1^{\text {'arc }}$ de courbe de croissance $C$ est différente de l'arc correspondant de la courbe $\mathrm{A}$ au moins jusqu'à $360 \mathrm{~g}$, mais on ne distingue pas de changement de sens de concavité.

\section{3. - ASPECT ET COMPORTEMENT}

Les animaux restreints consomment leur ration en 8 heures environ au début de l'expérience. Ce temps diminue progressivement jusqu'à $I / 2$ heure au bout de quelques jours. Les animaux sont donc pratiquement à jeun au moins 17 heures sur 24 . Ils se caractérisent extérieurement des témoins par leur maigreur et un pelage terne. La réalimentation leur redonne en deux semaines un aspect normal.

\section{4. - COMPOSITION GLOBALE DES CORPS ÉViscÉRÉS DES ANIMAUX DES SÉRIES I ET II}

Les résultats sont portés dans le tableau 3. Le maintien à poids constant des animaux en croissance s'accompagne d'une perte d'eau et de lipides et d'un gain de matières azotées totales (M. A. T.) et de cendres. Le gain en M. A. T. varie de 22 à $3 \mathrm{I}$ p. Ioo suivant le stade et le gain en cendres de IOO à $87 \mathrm{p}$. IOO. Les pertes en lipides sont respectivement de 37 et 38 p. Ioo.

Entre 70 et $200 \mathrm{~g}$, les animaux réalimentés retiennent chaque jour un excès de lipides par rapport aux animaux en croissance normale (tab1. $3 \mathrm{c}$ ). Ceci correspond à l'augmentation d'appétit constatée pendant cette période (fig. I). Cette très forte accumulation est temporaire ; elle permet aux animaux non seulement de rattraper le retard pris pendant la période de maintien à poids constant, mais encore d'accumuler un supplément de lipides. La rétention journalière d'eau est plus forte chez les animaux réalimentés. En revanche, les quantités de $M$. A. T. et de minéraux retenues chaque jour correspondent pratiquement à ce qu'elle est chez des témoins de même poids.

\section{5. - Évolution DES TENEURS EN ACIDES NUCLÉIQUES ET EN PROTÉINES}

Série I (lots $I_{A}$ et $I_{B}$ ) (tab1. 4).

Foie. - Chez le lot $\mathrm{I}_{\mathbf{B}}$, le poids frais du foie est diminué de $3 \mathrm{I}$ p. Ioo et la quantité de protéines de $15 \mathrm{p}$. IOO. La diminution de $2,4 \mathrm{p}$. I00 de l'ADN paraitt insignifiante. Le passage de la valeur du rapport ARN/ADN de 3,5 à 2,4 correspond à une perte de près de $32 \mathrm{p}$. Ioo de la quantité initiale d'ARN.

Musculature des membres inférieurs. - Chez le lot $\mathrm{I}_{\mathrm{B}}$, le poids frais de l'ensemble musculaire étudié n'a pas varié, tandis que les quantités d'ADN et de protéines augmentent : la première légèrement, soit de $9 \mathrm{p}$. Ioo, la seconde très 
nettement, soit de 24 p. IOo. L'ARN, en revanche, accuse une perte sévère de 49 p. Ioo, ce qui fait passer la valeur du rapport ARN/ADN de I,8 à 0,8 .

\section{TABLEAU 4}

Infuence de la réduction de l'apport énergétique de la ration sur les teneurs en acides nucléiques et en protéines du foie

et des tissus chez le Rat

Série I : animaux de $7 \circ \mathrm{g}: \mathrm{I}^{\circ}$ témoins $\left(\mathrm{I}_{\mathrm{A}}\right), 2^{\circ}$ maintenus à poids constant pendant 42 jours $\left(\mathrm{I}_{\mathrm{B}}\right)$.

Série II : animaux de $200 \mathrm{~g}$ : $\mathrm{I}^{\circ}$ témoins $\left(\mathrm{II}_{\mathrm{A}}\right)$, $2^{\circ}$ préalablement maintenus à $70 \mathrm{~g}$ pendant 42 jours $\left(\mathrm{II}_{\mathrm{B}}\right), 3^{\circ}$ maintenus à $200 \mathrm{~g}$ pendant 42 jours $\left(\mathrm{II}_{\mathrm{C}}\right)$.

\begin{tabular}{|c|c|c|c|c|c|c|c|c|}
\hline \multirow[b]{2}{*}{. } & \multicolumn{4}{|c|}{ Série I } & \multicolumn{4}{|c|}{ Série II } \\
\hline & $\begin{array}{l}\text { No des } \\
\text { lots }\end{array}$ & Foie & $\begin{array}{l}\text { Muscles } \\
\text { MP (1) }\end{array}$ & $\begin{array}{l}\text { Corps } \\
\text { éviscéré }\end{array}$ & $\begin{array}{l}\text { No des } \\
\text { lots }\end{array}$ & Foie & $\begin{array}{l}\text { Muscles } \\
\operatorname{MP}(1)\end{array}$ & $\begin{array}{l}\text { Corps } \\
\text { éviscéré }\end{array}$ \\
\hline Poids frais $(\mathrm{g})$ & $\begin{array}{l}\mathrm{I}_{\mathbf{A}} \\
\mathrm{I}_{\mathbf{B}}\end{array}$ & $\begin{array}{l}3,9 \\
2,7\end{array}$ & $\begin{array}{l}4,7 \\
4,8\end{array}$ & $\begin{array}{l}48,2 \\
48\end{array}$ & $\begin{array}{l}I I_{A} \\
I I_{B} \\
I_{C}\end{array}$ & $\begin{array}{l}9,4 \\
8,7 \\
6,2\end{array}$ & $\begin{array}{l}17,2 \\
15,8 \\
18,8\end{array}$ & $\begin{array}{l}145,0 \\
145,0 \\
146,0\end{array}$ \\
\hline Poids frais \% PV (2) & $\begin{array}{l}\mathbf{I}_{\mathbf{A}} \\
\mathbf{I}_{\mathbf{B}}\end{array}$ & $\begin{array}{l}6,0 \\
3,8\end{array}$ & $\begin{array}{l}6,6 \\
6,7\end{array}$ & $\begin{array}{l}68,9 \\
66,7\end{array}$ & $\begin{array}{l}\mathrm{II}_{\mathrm{A}} \\
\mathrm{II}_{\mathrm{B}} \\
\mathrm{II}_{\mathrm{C}}\end{array}$ & $\begin{array}{l}4,7 \\
4,3 \\
3,1\end{array}$ & $\begin{array}{l}8,6 \\
7,9 \\
9,3\end{array}$ & $\begin{array}{c}72,4 \\
72,4 \\
72,6\end{array}$ \\
\hline Poids SD $\left({ }^{3}\right)(\mathrm{g})$ & $\begin{array}{l}\mathrm{I}_{\mathrm{A}} \\
\mathrm{I}_{\mathrm{B}}\end{array}$ & $\begin{array}{l}0,72 \\
0,58\end{array}$ & $\begin{array}{l}0,83 \\
1,00\end{array}$ & $\begin{array}{r}8,8 \\
10,9\end{array}$ & $\begin{array}{l}\mathrm{II}_{\mathrm{A}} \\
\mathrm{II}_{\mathrm{B}} \\
\mathrm{II}_{\mathrm{C}}\end{array}$ & $\begin{array}{l}1,7 \\
1,7 \\
1,4\end{array}$ & $\begin{array}{l}3,3 \\
3,0 \\
4,4\end{array}$ & $\begin{array}{l}26,3 \\
24,0 \\
36,0\end{array}$ \\
\hline Protéines totales $(\mathbf{4})(\mathrm{g})$ & $\begin{array}{l}\mathrm{I}_{\mathrm{A}} \\
\mathrm{I}_{\mathrm{B}}\end{array}$ & $\begin{array}{l}0,59 \\
0,50\end{array}$ & $\begin{array}{l}0,67 \\
0,83\end{array}$ & $\begin{array}{l}7,3 \\
9,0\end{array}$ & $\begin{array}{l}\mathrm{II}_{\mathrm{A}} \\
\mathrm{II}_{\mathrm{B}} \\
\mathrm{II}_{\mathrm{C}}\end{array}$ & $\begin{array}{l}1,4 \\
1,4 \\
1,2\end{array}$ & $\begin{array}{l}2,7 \\
2,6 \\
3,5\end{array}$ & $\begin{array}{l}22,8 \\
20,3 \\
30,1\end{array}$ \\
\hline ADN total ( $\mu \mathrm{M}$-bases $)$ & $\begin{array}{l}\mathrm{I}_{\mathrm{A}} \\
\mathrm{I}_{\mathrm{B}}\end{array}$ & $\begin{array}{l}25,0 \\
24,4_{k}\end{array}$ & $\begin{array}{l}14,3 \\
15,6\end{array}$ & $\begin{array}{l}290 \\
245\end{array}$ & $\begin{array}{l}\mathrm{II}_{\mathrm{A}} \\
\mathrm{II}_{\mathrm{B}} \\
\mathrm{II}_{\mathrm{C}}\end{array}$ & $\begin{array}{l}57,0 \\
58,5 \\
54,1\end{array}$ & $\begin{array}{l}33,8 \\
32,4 \\
35,0\end{array}$ & $\begin{array}{l}518 \\
502 \\
515\end{array}$ \\
\hline$\frac{\text { Poids frais (mg) }}{\text { ADN }}$ & $\begin{array}{l}\mathrm{I}_{\mathrm{A}} \\
\mathrm{I}_{\mathrm{B}}\end{array}$ & $\begin{array}{l}156 \\
111\end{array}$ & $\begin{array}{l}327 \\
308\end{array}$ & $\begin{array}{l}166 \\
196\end{array}$ & $\begin{array}{l}\mathrm{II}_{\mathrm{A}} \\
\mathrm{II}_{\mathrm{B}} \\
\mathrm{II}_{\mathrm{C}}\end{array}$ & $\begin{array}{l}165 \\
149 \\
115\end{array}$ & $\begin{array}{l}509 \\
488 \\
537\end{array}$ & $\begin{array}{l}280 \\
289 \\
283\end{array}$ \\
\hline$\frac{\text { Protéines (mg) }}{\text { ADN (uM-bases) }}$ & $\begin{array}{l}\mathrm{I}_{\mathrm{A}} \\
\mathrm{I}_{\mathrm{B}}\end{array}$ & $\begin{array}{l}23.6 \\
20,5\end{array}$ & $\begin{array}{l}46,9 \\
53,2\end{array}$ & $\begin{array}{l}25,2 \\
36,7\end{array}$ & $\begin{array}{l}\mathrm{II}_{\mathrm{A}} \\
\mathrm{II}_{\mathrm{B}} \\
\mathrm{II}_{\mathrm{C}}\end{array}$ & $\begin{array}{l}24,6 \\
23,9 \\
22,2\end{array}$ & $\begin{array}{c}79,9 \\
80,2 \\
100\end{array}$ & $\begin{array}{l}44,0 \\
40,4 \\
58,4\end{array}$ \\
\hline $\mathrm{ARN} / \mathrm{ADN}$ & $\begin{array}{l}\mathrm{I}_{\mathrm{A}} \\
\mathrm{I}_{\mathrm{B}}\end{array}$ & $\begin{array}{l}3,5 \\
2,4\end{array}$ & $\begin{array}{l}1,8 \\
0,8\end{array}$ & $\begin{array}{l}1,2 \\
0,7\end{array}$ & $\begin{array}{l}\mathrm{II}_{\mathrm{A}} \\
\mathrm{II}_{\mathrm{B}} \\
\mathrm{II}_{\mathrm{C}}\end{array}$ & $\begin{array}{l}3,7 \\
3,1 \\
2,3\end{array}$ & $\begin{array}{l}2,0 \\
1,7 \\
1,1\end{array}$ & $\begin{array}{l}1,2 \\
1,3 \\
0,8\end{array}$ \\
\hline
\end{tabular}

(1) Musculature des membres postérieurs.

(2) $\mathrm{PV}=$ Poids vif.

(3) $\mathrm{SD}=$ Seç et dégraissé.

(4) $\mathrm{N}$ acido-précipitable $\times 6,25$.

Corps éviscéré. - Le poids frais du corps éviscéré est comparable chez l'un 
et l'autre lot. Cependant, on note chez le lot $\mathrm{I}_{B}$ un gain de $23 \mathrm{p}$. Ioo en protéines, une perte de 15,5 p. Ioo en ADN et de 46,5 p. Ioo en ARN.

En résumé : on observe dans le foie des animaux maintenus à poids constant à un âge (et/ou à un poids) très inférieur à celui de la puberté, par réduction des éléments énergétiques de la ration, uneinhibition del'hyperplasie et une diminution des contenus cellulaires. Cette diminution intéresse des composés non protéiques et, dans une moindre mesure, les protéines. La musculature est moins sévèrement touchée, puisque les cellules peuvent accroitre un peu leur nombre et s'enrichir notablement en protéines. L'ensemble complexe que constitue le corps éviscéré accuse seul une perte d'ADN, donc de cellules ; cette perte ne pouvant pas être imputée à la musculature, comme nous venons de le voir, il faut supposer que d'autres tissus dégénèrent sous l'action de la carence énergétique. On peut penser aux tissus adipeux et à la peau (DURAND, travail en cours) dont la mobilisation partielle permet d'assurer une croissance résiduaire de tissus considérés comme prioritaires (musculaires et osseux). L'appauvrissement important en ARN est une caractéristique commune aux trois compartiments étudiés.

Série II (lots $\mathrm{II}_{\mathrm{A}}-\mathrm{II}_{\mathrm{B}}-\mathrm{II}_{\mathrm{C}}$ ) (tabl. 4).

Foie. - Le foie des animaux du lot II est très comparable à celui des témoins : poids frais très voisin, mêmes teneurs en $A D N$ et en protéines. La différence la plus importante concerne l'ARN, avec une infériorité de $\mathrm{r}_{3} \mathrm{p}$. roo au détriment du lot $\mathrm{II}_{\mathrm{B}}$. Ainsi, après deux semaines de réalimentation, le foie des animaux du parcours $B$ possède des caractéristiques qui ne sont pas différentes de celles du foie des témoins. Il en va autrement pour le lot $\mathrm{II}_{\mathbf{C}}$, dont le foie se révèle inférieur à celui des témoins de $34 \mathrm{p}$. Ioo en poids frais, de $\mathrm{I}_{4} \mathrm{p}$. Ioo en protéines, de $5 \mathrm{p}$. Ioo en $\mathrm{ADN}$ et de 40 p. IOo en ARN.

Ainsi, le foie des animaux $\mathrm{II}_{\mathrm{C}}$ présente à peu près les mêmes écarts relatifs avec le lot $I_{A}$ que le lot $I_{B}$ avec le lot $I_{A}$. De plus, les valeurs du rapport ARN/ADN et du rapport poids frais/ADN sont de même ordre chez les rats $I_{B}$ et $I_{C}$.

Musculature des membres postérieurs. - Pour le lot $\mathrm{II}_{\mathrm{B}}$, le poids frais de l'ensemble musculaire considéré est inférieur, de $8 \mathrm{p}$. Ioo, à ce qu'il est chez les témoins, tandis que les teneurs en protéines et en ADN sont équivalentes. L'écart le plus important concerne l'ARN, plus faible de I 8 p. Ioo chez les rats expérimentaux. La comparaison du même ensemble musculaire entre les lots $\mathrm{II}_{\mathrm{C}}$ et $\mathrm{II}_{\mathrm{A}}$ conduisent, comme dans le cas du foie, à des observations semblables à celles qui ont été retenues de la comparaison entre les lots $I_{B}$ et $I_{A}$ : au cours du maintien à poids constant on peut noter une très légère augmentation du poids frais et de l'ADN, une nettè augmentation de la teneur en protéines, voisine de $30 \mathrm{p}$. 100, enfin une diminution considérable de l'ARN de près de $45 \mathrm{p}$. Ioo.

Corps éviscéré. - Les corps éviscérés des rats $\mathrm{II}_{\mathrm{B}}$ ont le même poids frais, la même teneur en $A D N$, une teneur en protéines légèrement plus faible de II $\mathrm{p}$. Ioo, et une teneur en $A R N$ légèrement supérieure de $9 \mathrm{p}$. Ioo, aux caractéristiques correspondantes du corps éviscéré des rats $\mathrm{II}_{\mathrm{A}}$. Dans l'ensemble, ces différences sont de peu d'importance. Entre les corps éviscérés des lots $\mathrm{II}_{\mathrm{C}}$ et $\mathrm{II}_{\mathrm{A}}$, il n'y a pas 
de différence notabie quant au poids frais et à la teneur en ADN. Cependant, chez les animaux du lot $\mathrm{II}_{\mathbf{C}}$, la teneur en protéines est plus forte de $32 \mathrm{p}$. Ioo.

En résumé: l'ensemble des résultats exposés ci-dessus montre que les animaux du lot $\mathrm{II}_{\mathrm{B}}$, préalablement maintenus au poids de $70 \mathrm{~g}$ pendant 42 jours et ensuite réalimentés, sont très comparables aux animaux à croissance normale du lot $\mathrm{II}_{\mathrm{A}}$, du moins quant aux caractéristiques étudiées. Ils ont comblé très rapidement le retard qui leur a été imposé. Quant aux animaux du lot $\mathrm{II}_{\mathrm{C}}$, maintenus à poids constant pendant la puberté, ils réagissent aux conditions de restriction énergétique de la même façon que les animaux impubères du lot $\mathrm{I}_{B}$ :

- diminution importante du poids frais et des protéines du foie ;

- inhibition totale ou partielle de l'hyperplasie et chute des teneurs en ARN dans les 3 compartiments étudiés ;

- augmentation des teneurs en protéines de la musculature et du corps éviscéré. Toutefois, contrairement à ce qui a été constaté à propos du lot $I_{B}$, la quantité globale de cellules du corps éviscéré du lot $\mathrm{II}_{\mathrm{C}}$ est égale à la quantité relevée chez les témoins de même poids. Cependant, il n'est pas certain que la répartition des cellules entre les divers tissus soit identique.

Série III (lots $\operatorname{III}_{\mathrm{A}}, \mathrm{III}_{\mathrm{B}}, \mathrm{III}_{\mathrm{C}}$ ) (tabl. 5).

Peau. - Chez les trois lots, le poids frais et la teneur en protéines de la peau sont très voisins. On ne discerne pas de différence entre les teneurs en ADN des deux lots expérimentaux, mais ceux-ci accusent une infériorité de $9 \mathrm{p}$. Ioo par rapport au lot témoin. Les teneurs en ARN varient comme les teneurs en ADN.

Tissus adipeux. - Les poids frais sont à peu près équivalents chez les trois lots. Pour les teneurs en protéines, les lots expérimentaux ne sont pas différents entre etux, mais sont désavantagés de I8 p. roo environ par rapport au lot témoin. De même, les tissus adipeux des animaux expérimentaux contiennent moins d'ADN que ceux des témoins, soit $7 \mathrm{p}$. Ioo pour le lot $\operatorname{III}_{\mathrm{B}}$ et $20 \mathrm{p}$. Ioo pour le lot $\mathrm{III}_{\mathrm{C}}$. Les valeurs du rapport ARN/ADN sont équivalentes dans les trois lots.

Viscères et sang. - Il y a quelques différences d'un lot à l'autre en ce qui concerne le poids frais et la teneur en protéines de cet ensemble très complexe. Mais ces données dépendent en partie des contenus intestinaux et toute conclusion serait hasardeuse. Pour ce qui est des acides nucléiques, on observe une remarquable homogénéité entre les trois lots.

Foie. - Pour l'ensemble des caractéristiques étudiées, il y a peu de différence entre les trois lots.

Musculature des membres postérieurs. - Les caractéristiques des deux lots expérimentaux sont équivalentes. En les comparant à celles du lot témoin, il n'apparaît pas de différence pour les teneurs en protéines, mais une infériorité de ro p. I00 pour 1'ADN et 1'ARN.

Carcasse. - Comme pour la musculature, les carcasses des animaux expérimentaux ne sont pas différentes entre elles. Elle se distinguent de la carcasse des témoins seulement par une infériorité de 12,4 p. Ioo en ADN et en ARN. 


\section{TABLEAU 5}

Influence de la réduction de l'apport énergétique de la ration, appliquée à deux stades différents de la croissance, sur la teneur en acides nucleiques et en protéines des divers compartiments corporels chez le Rat adulte $(700 \mathrm{~g}): \mathrm{I}^{\circ}$ témoins $\left(\mathrm{III}_{\mathrm{A}}\right), 2^{\circ}$ préalablement maintenus à $70 \mathrm{~g}$ pendant 42 jours $\left(\mathrm{III}_{\mathrm{B}}\right), 3^{\circ}$ préalablement maintenus à $200 \mathrm{~g}$ pendant 42 jours (III $\left.\mathrm{C}\right)$.

\begin{tabular}{|c|c|c|c|c|c|c|c|}
\hline & $\begin{array}{l}\text { No des } \\
\text { lots }\end{array}$ & Peau & $\begin{array}{c}\text { Tissus } \\
\text { adipeux }\end{array}$ & $\begin{array}{l}\text { Viscères } \\
\text { + sang }\end{array}$ & Foie & $\begin{array}{l}\text { Muscles } \\
\text { MP (I) }\end{array}$ & Carcasse \\
\hline Poids frais (g) & $\begin{array}{l}\mathrm{III}_{A} \\
\mathrm{III}_{\mathbf{B}} \\
\mathrm{III}_{\mathrm{O}}\end{array}$ & $\begin{array}{l}112 \\
120 \\
108\end{array}$ & $\begin{array}{l}195 \\
200 \\
210\end{array}$ & $\begin{array}{l}68,7 \\
68,6 \\
63\end{array}$ & $\begin{array}{l}18,9 \\
21 ; 3 \\
22\end{array}$ & $\begin{array}{l}48 \\
41,8 \\
43\end{array}$ & $\begin{array}{l}235 \\
223 \\
235\end{array}$ \\
\hline $\begin{array}{l}\text { Poids frais } \\
\left.\% \text { PVR ( }{ }^{2}\right)\end{array}$ & $\begin{array}{l}\mathrm{III}_{\mathrm{A}} \\
\mathrm{III}_{\mathbf{B}} \\
\mathrm{III}_{\mathrm{C}}\end{array}$ & $\begin{array}{l}16,5 \\
17,8 \\
15,9\end{array}$ & $\begin{array}{l}28,8 \\
29,6 \\
30,8\end{array}$ & $\begin{array}{r}10,1 \\
10,2 \\
9,3\end{array}$ & $\begin{array}{l}2,8 \\
3,2 \\
3,2\end{array}$ & $\begin{array}{l}7,1 \\
6,2 \\
6,3\end{array}$ & $\begin{array}{l}34,7 \\
33,0 \\
34,5\end{array}$ \\
\hline Poids SD $\left(^{(3)}(\mathrm{g})\right.$ & $\begin{array}{l}\mathrm{III}_{\mathrm{A}} \\
\mathrm{III}_{\mathrm{B}} \\
\mathrm{III}_{\mathrm{C}}\end{array}$ & $\begin{array}{l}30,8 \\
30,5 \\
31,4\end{array}$ & $\begin{array}{l}5,2 \\
4,3 \\
4,4\end{array}$ & $\begin{array}{l}7,8 \\
8,4 \\
7,1\end{array}$ & $\begin{array}{l}3,7 \\
3,8 \\
3,7\end{array}$ & $\begin{array}{l}9,7 \\
8,6 \\
9,8\end{array}$ & $\begin{array}{l}45,8 \\
42,4 \\
41,8\end{array}$ \\
\hline $\begin{array}{c}\text { Protéines } \\
\text { totales (4) (g) }\end{array}$ & $\begin{array}{l}\mathrm{III}_{\mathbf{A}} \\
\mathrm{III}_{\mathbf{B}} \\
\mathrm{III}_{\mathrm{C}}\end{array}$ & $\begin{array}{l}28,4 \\
28,4 \\
28,8\end{array}$ & $\begin{array}{l}4,8 \\
4,0 \\
3,9\end{array}$ & $\begin{array}{l}6,7 \\
7,4 \\
6,5\end{array}$ & $\begin{array}{l}3,3 \\
3,3 \\
3,2\end{array}$ & $\begin{array}{l}8,4 \\
7,9 \\
8,3\end{array}$ & $\begin{array}{l}39,4 \\
37,6 \\
38,6\end{array}$ \\
\hline $\begin{array}{l}\text { ADN total } \\
\text { ( } \mu \mathrm{M} \text {-bases) }\end{array}$ & $\begin{array}{l}\operatorname{III}_{A} \\
\operatorname{III}_{B} \\
\operatorname{IIII}_{C}\end{array}$ & $\begin{array}{l}306 \\
281 \\
276\end{array}$ & $\begin{array}{l}133 \\
123 \\
107\end{array}$ & $\begin{array}{l}340 \\
346 \\
331\end{array}$ & $\begin{array}{l}125 \\
125 \\
115\end{array}$ & $\begin{array}{l}64 \\
57 \\
58\end{array}$ & $\begin{array}{l}545 \\
488 \\
477\end{array}$ \\
\hline$\frac{\text { Poids frais (mg) }}{\text { ADN ( } \mu \text { M-bases) }}$ & $\begin{array}{l}\mathrm{III}_{\mathbf{A}} \\
\mathrm{III}_{\mathbf{B}} \\
\mathrm{III}_{\mathbf{C}}\end{array}$ & $\begin{array}{l}366 \\
428 \\
391\end{array}$ & $\begin{array}{l}1466 \\
1626 \\
1962\end{array}$ & $\begin{array}{l}202 \\
198 \\
190\end{array}$ & $\begin{array}{l}151 \\
170 \\
191\end{array}$ & $\begin{array}{l}750 \\
733 \\
741\end{array}$ & $\begin{array}{l}431 \\
547 \\
493\end{array}$ \\
\hline$\frac{\text { Protéines (mg) }}{\text { ADN ( } \mu \text { M-bases) }}$ & $\begin{array}{l}\text { III }_{\mathbf{A}} \\
\operatorname{III}_{\mathbf{B}} \\
\mathrm{III}_{\mathrm{C}}\end{array}$ & $\begin{array}{r}93 \\
101 \\
104\end{array}$ & $\begin{array}{l}36 \\
32 \\
36\end{array}$ & $\begin{array}{l}19,7 \\
21,4 \\
19,6\end{array}$ & $\begin{array}{l}26 \\
26 \\
28\end{array}$ & $\begin{array}{l}131 \\
138 \\
143\end{array}$ & $\begin{array}{l}72,3 \\
77,0 \\
80,1\end{array}$ \\
\hline ARN/ADN & $\begin{array}{l}\mathrm{III}_{\mathbf{A}} \\
\text { III }_{\mathrm{B}} \\
\mathrm{IIII}_{\mathrm{C}}\end{array}$ & $\begin{array}{l}1,0 \\
1,1 \\
1,0\end{array}$ & $\begin{array}{l}1,1 \\
1,1 \\
1,0\end{array}$ & $\begin{array}{l}1,1 \\
1,1 \\
1,1\end{array}$ & $\begin{array}{l}3,0 \\
3,0 \\
3,0\end{array}$ & $\begin{array}{l}1,6 \\
1,6 \\
1,7\end{array}$ & $\begin{array}{l}1,1 \\
1,1 \\
1,1\end{array}$ \\
\hline
\end{tabular}

(1) Musculature des membres postérieurs.

(2) $\mathrm{PVR}=$ Poids vif reconstitué.

( $) \mathrm{SD}=$ Sec et dégraissé.

(4) $\mathrm{N}$ acido précipitable $\times 6,25$. 


\section{6. - QUaNTITÉs TOTALES D'ACIDES NUCLÉIOUES ET DE PROTÉINES (tabl. 6)}

En faisant la somme des quantités des protéines et de chacun des acides nucléiques contenus en moyenne par les animaux de chaque lot, il apparaît que, pour les acides nucléiques, les animaux expérimentaux sont désavantagés par rapport aux témoins. Le lot le plus désavantagé, III $\mathrm{C}_{\mathrm{C}}$, est inférieur de $9,8 \mathrm{p}$. Ioo pour l'ADN et de 9 p. Ioo pour l'ARN. Pour les protéines, le lot le plus désavantagé, $\operatorname{III}_{B}$, est inférieur au témoin de 2,6 p. I00, ce qui ne peut être pris en considération.

\section{TABLEAU 6}

Influence de la réduction de l'apport énergétique de la ration, appliquée à deux stades différents de la croissance sur les contenus totaux en $A D N$, protéines et $A R N$ du Rat adulte (700 g) : $1^{\circ}$ témoins $\left(\mathrm{III}_{\mathrm{A}}\right), 2^{\circ}$ préalablement maintenus à $70 \mathrm{~g}$ pendant $4^{2}$ jours $\left(\mathrm{III}_{\mathrm{B}}\right), 3^{\circ}$ préalablement maintenus à $200 \mathrm{~g}$ pendant 42 jours (IIIc).

\begin{tabular}{|c|c|c|c|}
\hline$N^{\circ}$ des lots & $\mathrm{III}_{A}$ & $\mathrm{III}_{\mathrm{B}}$ & $\mathrm{III}_{\mathrm{c}}$ \\
\hline $\begin{array}{l}\text { ADN }\left(\mu \mathrm{M} \text {-bases }\left({ }^{1}\right)\right) \\
\text { Protéines }\left(^{2}\right)(\mathrm{g}) \ldots \\
\text { ARN }(\mu \mathrm{M} \text {-bases) } \ldots\end{array}$ & $\begin{array}{r}1513 \\
91 \\
1882\end{array}$ & $\begin{array}{c}1420 \\
88,6 \\
1824\end{array}$ & $\begin{array}{c}1364 \\
89,3 \\
1712\end{array}$ \\
\hline
\end{tabular}

(1) $1 \mu \mathrm{M}$-bases $=31 \mu \mathrm{g}$ P-ADN ou P-ARN.

(2) N acido précipitable $\times 6,25$.

\section{7. - RÉPARTITION DE L'ADN ET DES PROTÉINES ENTRE LES DIVERS COMPARTIMENTS CORPORELS (tabl. 7 )}

Les protéines se répartissent pratiquement de la même manière entre les différents compartiments corporels des trois lots de la série III, si ce n'est une légère supériorité du lot témoin pour les protéines des tissus adipeux.

Les deux lots expérimentaux $\mathrm{II}_{\mathrm{B}}$ et $\mathrm{II}_{\mathrm{C}}$ se distinguent par une proportion légèrement accrue de $1^{\prime} \mathrm{ADN}$ des viscères $(24,4 \mathrm{p}$. Ioo au lieu de 22,5). Mais cet écart a peu de retentissement sur l'ensemble des répartitions qui sont finalement très comparables dans les trois lots. On remarque la part importante de la peau (20 p. Ioo de l'ADN total et $32 \mathrm{p}$. Ioo des protéines). Il est vrai que cette dernière représente, chez des animaux de petite taille comme le Rat, une fraction élevée du poids vif. En revanche, eu égard à leur importance pondérale (29 à $30 \mathrm{p}$. roo du poids vif) les tissus adipeux disséqués ne contiennent que 8 à 9 p. roo de l'ADN total. En fait, là dissection ne permet pas de rassembler toutes les cellules adipeuses; il en reste dans la moelle osseuse, entre les muscles, et dans les viscères. Les résultats relatifs aux tissus adipeux sont donc inférieurs à la réalité. Cependant, les tissus adipeux tels que nous les avons disséqués contiennent 60 à 70 p. Ioo des lipides contenus dans le corps entier. Si tous les lipides répartis dans les cinq autres compartiments disséqués étaient exclusivement contenus dans des cellules adipeuses sensu stricto, ce qui est absurde, le 
nombre total des cellules adipeuses ne pourrait dépasser $\frac{9 \times \text { I00 }}{60}=$ I5 p. I00 du capital cellulaire de 1'animal. En définitive, il semble raisonnable d'admettre que chez

\section{TABLEAU 7}

Infuence de la réduction de l'apport énergétique de la ration, appliquée à deux stades différents de la croissance, sur la répartition de l'ADN et des proteines entre différents compartiments corporels chez le Rat adulte $(700 \mathrm{~g}): \mathrm{I}^{\circ}$ témoins $\left(\mathrm{III}_{\mathrm{A}}\right), 2^{\circ}$ préalablement maintenus à $70 \mathrm{~g}$ pendant 42 jours (III $), 3^{\circ}$ préalablement maintenus à $200 \mathrm{~g}$ pendant 42 jours (III $)$.

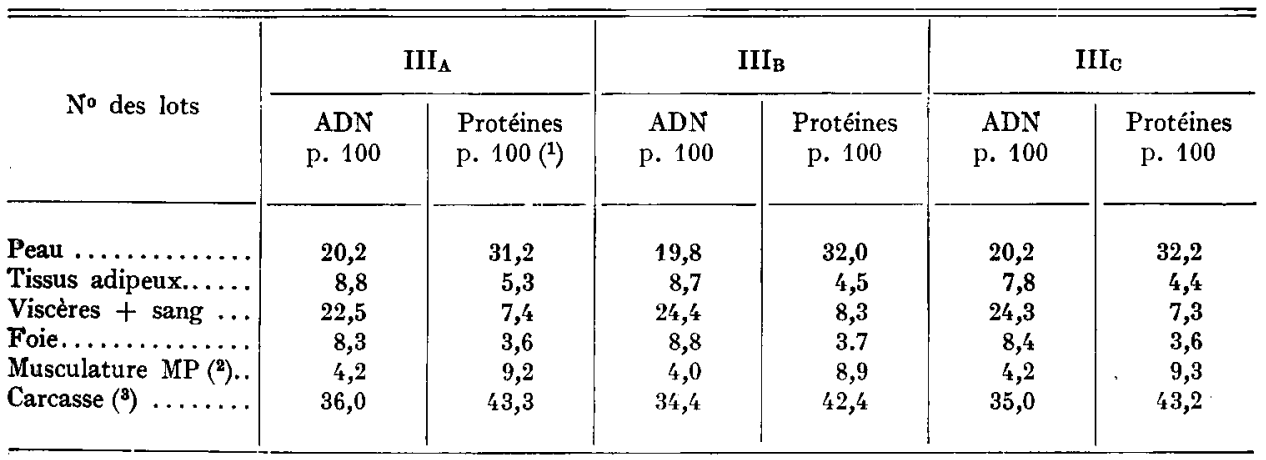

(1) $\mathrm{N}$ acido-précipitable $\times 6,25$.

(2) Musculature des membres postérieurs.

(3) Reste du corps, comprenant essentieliement la musculature (moins celle des membres postérieurs), et le squelette.

le Rat adulte et gras, le nombre de cellules adipeuses ne représente pas plus de Io-II p. roo du nombre total de cellules.

\section{8. - RAPPORT ARN/ADN}

Il apparaît que dans les compartiments où dominent les tissus de types épithéliaux conjonctifs (peau, tissus adipeux, viscères) le rapport ARN/ADN est d'une remarquable homogénéité et sa valeur est comprise entre $I, O$ et $I, I$. Le foie (type épithélium glandulaire) fait exception à la règle, avec une valeur plus élevée.

Dans le tissu musculaire, le rapport ARN/ADN varie entre $I, 6$ et $I, 7$. Sachant que le muscle comprend environ 20 à $35 \mathrm{p}$. Ioo de cellules de type conjonctif (ENEsco et Deli,a Puddy, I964; Marchor et Herrrmann, ig67), un calcul simple montre que le rapport ARN/ADN des fibres musculaires a une valeur au moins égale à r,9.

\section{DISCUSSION}

\section{a) Maintien à poids constant}

Dans le présent travail, des rats sont maintenus pendant 42 jours à poids constant uniquement par réduction de l'apport énergétique de la ration, soit un peu après le sevrage ( $70 \mathrm{~g}, 4$ semaines), soit au moment de la puberté ( $200 \mathrm{~g}, 7$ semaines). La 
durée de maintien à poids constant correspond approximativement à $5 \mathrm{p}$. Ioo de l'espérance de vie de l'animal (KAYSER et al., I966).

Il ressort des résultats que la teneur en protéines du corps éviscéré de ces animaux peut augmenter de $23 \mathrm{p}$. Ioo pour les premiers, de $32 \mathrm{p}$. Ioo pour les seconds. Cela les situe respectivement, eu égard aux protéines, au niveau d'animaux témoins de $86 \mathrm{~g}$ et $260 \mathrm{~g}$. On constate par ailleurs, qu'ils perdent une partie de leurs lipides. On peut penser que l'énergie ainsi libérée est utilisée pour permettre à des compartiments corporels prioritaires (certains organes, musculature, squelette) d'accumuler une quantité supplémentaire de protéines, accumulation correspondant à une croissance résiduaire. La proportion de lipides perdus est équivalente $(37-38 \mathrm{p}$. Ioo) aux deux stades étudiés. Les animaux restreints à un stade plus tardif, ayant une teneur relative en lipides plus élevée, mobilisent donc proportionnellement plus d'énergie et peut-être cela leur permet-il d'augmenter relativement plus la teneur en protéines de leurs tissus.

Ainsi le maintien à poids constant par restriction énergétique n'entraîne pas un retard de croissance aussi grand que ne le laisse supposer le seul examen du poids vif, et le retard réel est d'autant plus faible que la restriction est appliquée plus tardivement. Ceci peut contribuer à expliquer les positions respectives des courbes de croissance.

Des travaux antérieurs (DURAND et al., I967) ont permis de montrer que lorsqu'on limite à $2 \mathrm{~g} / \mathrm{jour}$, par restriction énergétique, le gain de poids journalier de rats en croissance, on freine fortement 1'hyperplasie dans les divers tissus, tandis que les cellules continuent à s'enrichir en protéines. Le maintien à poids constant constitue un cas limite du cas précédent : les résultats présentés ci-dessous montrent que lorsque le gain de poids est nul, 1'hyperplasie est pratiquement stoppée, tandis que là encore, les cellules accroissent leur capital protéique. La quantité d'énergie disponible apparaît comme un élément très important de la synthèse de 1'ADN. Les mécanismes biochimiques par lesquels l'énergie intervient dans cette synthèse restent à élucider. Quant à la chute de 1'ARN, elle est sans doute le résultat global apparent de nombreux remaniements de son métabolisme, remaniements dont certains aspects ont été décrits dans le cas de régimes carencés en un acide aminé indispensable ou en régime sans protéines (FLECK et al., I955; QUIRIN-STRICKER et MENDEL, I967-I968; Young et al., I968).

\section{b) Réalimentation}

Lorsque les animaux peuvent de nouveau s'alimenter à satiété en énergie, on distingue deux périodes successives : l'une d'une durée limitée à $2-3$ semaines pendant laquelle le gain de poids quotidien est supérieur à ce qu'il est chez des témoins de même poiđs, l'autre, pendant laquelle témoins et expérimentaux se développent, soit au même rythme, en ce qui concerne les animaux du lot III $_{C}$, soit peut-être un peu plus lentement, en ce qui concerne les animaux du lot $\operatorname{III}_{\mathrm{B}}$. Cependant, entre 400 et $700 \mathrm{~g}$, la vitesse moyenne de croissance de ces derniers est de I,5I g/jour, tanđis que celle des témoins est de $I, 5^{8} \mathrm{~g} /$ jour. Un écart aussi faible ne permet pas de conclure que la vitesse de croissance des uns et des autres est significativement différente. Pendant la première période, l'appétit est très augmenté et il se produit une accumulation de lipides qui permet à l'animal non seulement de reconstituer ce 
qu'il avait perdu, mais encore de dépasser ce qu'on peut attendre chez des témoins de même poids. En revanche, il n'y a pas de différence sensible entre les quantités de protéines et de minéraux retenus chaque jour par les rats en croissance normale et en croissance compensatrice. Ce phénomène d'engraissement exagéré qui suit une période de sous-nutrition a déjà été montré par de nombreux auteurs (HEGGENESS, I96I $a, b$; FABRY et $a l$., I962 ; MoRin-Jomain et ABRAHam, I965). En même temps il se produit une reprise vigoureuse de la multiplication cellulaire dans l'ensemble du corps, qui permet aux animaux restreints de rattraper une partie du " temps perdu " puisque, par exemple, les rats maintenus à $70 \mathrm{~g}$ peuvent édifier en $\mathrm{I}_{5}$ jours autant de cellules que des animaux normaux en 22 jours.

A la fin de la première période, les rats expérimentaux se retrouvent avec un surplus de lipides. Or, arrivés au bout de plus de 200 jours de récupération, leur teneur en lipides n'est pas significativement supérieure à celle des témoins. Il s'est donc produit un phénomène de régulation. En première analyse, on pourrait penser qu'une diminution passagère ou régulière de l'appétit soit en cause. Une légère diminution de l'ingestion alimentaire a effectivement été constatée dans un cas (parcours B) mais non dans 1'autre (parcours C). D'autres facteurs de régulation, agissant directement au niveau du métabolisme lipidique, étudiés par HAGENFss et les auteurs précédemment cités, interviennent vraisemblablement.

Toujours est-il que, lorsque les animaux sont adultes et comparés à poids égal, la répartition des divers tissus et leurs teneurs en protéines ne sont pas différentes quel que soit le régime alimentaire antérieurement suivi.

Par ailleurs, les quantités totales de cellules et leurs répartitions entre les compartiments corporels diffèrent peu entre les rats réalimentés adultes, mais elles sont légèrement inférieures, de Io $\mathrm{p}$. Ioo en moyenne, à ce qu'elles sont chez les témoins correspondants. Les méthodes utilisées ne permettant pas d'établir de comparaison statistique, un doute subsiste sur la signification d'un écart aussi modeste. Dans 1'hypothèse où sa signification pourrait être démontrée, sa cause demeurerait obscure : on a vu en effet qu'après deux semaines de réalimentation, les rats expérimentaux contenaient autant de cellules que les témoins de même poids. Il n'apparaît pas pourquoi, ultérieurement, l'hyperplasie n'évoluerait pas parallèlement chez les expérimentaux et les témoins, comme c'est le cas pour la plupart des caractéristiques étudiées, d'autant plus que ce sont les animaux du lot $\mathrm{III}_{\mathrm{C}}$, dont le poids, au-delà de $200 \mathrm{~g}$, se rapproche le plus rapidement de celui des témoins, qui sont les plus désavantagés à cet égard.

Dans ces conditions, nos résultats n'apportent pas de confirmation aux conclusions de WINICK et NoBLE ( 1966 ), qui prétendent que des rats restreints pendant une durée de 3 semaines à partir du sevrage ne peuvent pas atteindre la taille adulte normale car ils ne peuvent plus augmenter suffisamment le nombre de leurs cellules. Il est vrai que ces auteurs ont utilisé un type de restriction différent de celui qui est appliqué dans le présent travail. Cependant, leur affirmation suivant laquelle les rats témoins ou expérimentaux cessent d'augmenter leur poids vers I20 jours paraît surprenante, de même que la forme des courbes de croissance tracées d'après leurs données numériques.

Quoi qu'il en soit, d'après nos résultats, une carence des éléments énergétiques de la ration imposée à des rats, soit au sevrage, soit plus tard, pendant 5 p. roo de 
leur espérance de vie, et assez sévère pour que le poids vif des animaux soit maintenu constant, n'interdit pas aux animaux d'atteindre le poids respectable de $700 \mathrm{~g}$. On peut considérer qu'à ce poids les animaux témoins n'accumulent plus de protéines et n'augmentent plus le nombre de leurs cellules. Or, les rats expérimentaux contiennent autant de protéines que les témoins et un nombre de cellules seulement légèrement plus faible. Par conséquent, il semble que la restriction passagère qui leur a été imposée ne leur ait pas interdit, avec un décalage de temps d'autant plus long que la restriction a été appliquée plus précocement, de devenir des adultes normaux. Ainsi, compte tenu de nos conditions expérimentales, nous n'arrivons donc pas aux mêmes conclusions que les auteurs cités dans l'introduction, mais nous rejoignons les données plus anciennes d'OSBORNE et MENDEL (I9I4-I9I5) d'après lesquels des rats peuvent toujours atteindre la taille adulte normale ( full size) caractéristique de leur espèce, consécutivement à des périodes très prolongées d'arrêt de croissance.

Il est possible qu'il n'en soit pas ainsi pour tous les types de carence alimentaire et pour toutes les espèces. Il est également possible qu'il n'en soit pas ainsi lorsque la restriction est appliquée pendant la période d'allaitement, ou pendant un temps beaucoup plus long : un travail est en cours sur ce dernier point.

Reşu pour publication en novembre 1968.

\section{SUMMARY}

DISTRIBUTION OF CELLS AMONG TISSUES OF ADULT RATS

PREVIOUSLY SUBJECTED TO TEMPORARY DEFICIENCY OF ENERGY IN THE DIET AT TWO STAGES OF GROWTH

Three groups of rats were fed to appetite from weaning on a balanced semi-synthetic diet with I3 per cent crude protein (control diet). They were killed at 70, 200 or $700 \mathrm{~g}$ and constituted the control groups.

Five experimental groups, formerly well fed, were kept at constant weight for 42 days by a reduction only of the sources of energy in the diet, the carbohydrates and lipids. For some groups this was shortly after weaning and for others it was at puberty. At the end of the period of restriction one group of each type was killed. The others were again given the control diet and the last of them were killed when they reached $700 \mathrm{~g}$ body weight.

Bodies were dissected and separated into several compartments, in which were estimated the content of deoxyribonucleic acid (DNA), proportional to the number of cells - the ratio of fresh weight to DNA, proportional to the size of the cells - and the ratios of proteins and of ribonucleic acid to DNA, indicative of cellular activity. that:

Experimental and control rats were compared at equal live weights. The main results showed

Maintenance at constant weight prevented hyperplasia and hypertrophy of cells but allowed the rats to accumulate a certain amount of protein and minerals at the expense of water and lipids.

Refeeding to appetite was followed by a period of 2 to 3 weeks during which hyperplasia was particularly intense and there was excessive accumulation of lipids.

After this phase of very active recovery the experimental rats developed either at the same rate as controls or slightly more slowly, depending on whether the restriction had been at puberty or at weaning.

When the rats reached $700 \mathrm{~g}$ the total amount of proteins and their distribution among the different body compartments were largely the same however the animals had previously been fed. The two types of experimental rats had practically the same amount of cells. However, they were more abundant, by ro per cent on average, in the controls. It is not certain that so small a difference should be considered. Distribution of the cells among the different body compartments was the same in control and experimental rats. 


\section{RÉFÉRENCES BIBLIOGRAPHIQUES}

Chargaff F., Lipshitz R., 1953. Composition of mammalian desoxyribonucleic acids. J. Amer. Chem. Soc., 75, 3658-366r.

Colowick S. P., KaPlan N. O. (Ed), I957. Methods in Enzymology, vol. 3, Section V.

Durand G., Fauconneau G., Penot E., I965. Étude biochimique de la croissance de l'intestin grêle, du foie et de la carcasse du Rat; rôles respectifs de la multiplication et du grandissement cellulaires. Ann. Biol. anim. Bioch. Biophys., 5, 163-187.

Durand G., Fauconneau G., Penot E., 1967. Croissance des tissus du Rat et réduction de l'apport énergétique de la ration ; influence sur la teneur en acides nucléiques. Ann. Biol. anim. Bioch. Biophys. 7, $145^{-1} 55$.

ENEsco M., PuDdy D., I964. Increase in the number of nuclei and weight in skeletal muscle of rats of various ages. Amer. J. Anat., 114, 235-244.

Fabry P., Petrasek R., Braun T., Bednarek M., Horakova E., Konopasek E., i962. Lipogenesis in Rats adapted to intermittent starvation or continuous underfeeding. Experientia, 18, 555-556.

Fleck A., Shepherd J, Munro H. N., I 965 . Protein synthesis in Rat liver : influence of amino acids in diet on microsomes and polysomes. Science, 150, 628-629.

Heggeness F. W., 196r. Weight gains and fat accumulation in Rats subjected to periods of caloric restriction. Amer. J. Physiol., 201, 1044-1048.

Kayser J., Neumann J., Lavollay J,, ig66. Sur la longévité du rat Wistar nourri ad libitum avec un régime semi-synthétique. C. R. Acad. Sci., 262, 2063-2065.

Levene P. A., Bass L. W., I93i. Nucleic acids, chemical catalog company, New York.

Lister D., McCANCE R. A., I 965 . The effect of two diets on the growth, reproduction and ultimate size of Guinea-pigs. Brit. J. Nutr., 18, 311-319.

Lister D., MCCANCE R. A., I967. Severe under nutrition in growing and adult animals. 17. The ultimate results of rehabilitation. Pigs. Br. J. Nutr., 21, 787-799.

MarchoK C., HerrmanN H., I967. Studies of muscle development. I. Changes in cell proliferation. Develop. Biol., 15, $129-155$.

Morin-Jomain M., Abraham J., I965. Comparaison entre les effets de deux types d'alimentation discontinue (séquences d'inanition totale ou de jeûne protéique) sur la croissance et la composition corporelle du Rat blanc. Arch. Sci. Physiol., 19, I3I-I40.

OsRorne T. B., MENDEL L. B., 1914. The suppression of growth and the capacity to grow. J. Biol. Chem., 18, $95^{-106 .}$

OsBboRne T. B., MendeL L. B., I915. The resumption of growth after long continued failure to grow. $J$. Biol. Chem., 28, 439-454.

Quirin-Stricker C., MENDEL P., I967. Influence d'un régime carencé en protéines sur la synthèse du l'ARN et des protéines du foie de Rat. Bull. Soc. Chim. Biol., 49, 151 7-1 527.

Quirin-STricker C., Mendel P., 1968. Étude du renouvellement de l'ARN des polysomes, de l'ARN de transfert et de l'ARN messager dans le foie du Rat soumis à un jeâne protéique. Bull. Soc. Chim. Biol., 50, 3I-46.

Schmidt G., TANnhauser S. J., 1945. A method for the determination of desoxyribonucleic acid, ribonucleic acid, and phosphoproteins in animal tissues. J. Biol. Chem., 161, 83-89.

Widdowson E. M., Kennedy G. C., I 962 . Rate of growth, mature weight and life-span. Proc. Roy. Soc., $B, 156,96-108$.

Widdowson E. M., MCCANCE R. A., I963. The effect of finite periods of under nutrition at different ages on the composition and subsequent development of the Rat. Proc. R. Soc., B, 158, 329-342.

Winick M., NoBle A., 1966. Cellular response in Rats during malnutrition at various ages. J. Nutr., 89, 300-306.

WiNick M., NoBle A., I967. Cellular response with increased feeding in neonatal Rats. J. Nutr., 91, I 79-I 82.

Young V. R., Chen S. C., McDonald J., I968. The sedimentation of rat skeletal muscle ribosomes. Effect of hydrocortisone, insulin and diet. Biochem. J., 106, 91 3-919. 